\title{
Moving beyond the Metaphor of Transfer of Learning
}

\author{
Paul Hager (University of Technology, Sydney) and Phil Hodkinson (University \\ of Leeds)
}

Learning transfer is an extraordinarily narrow and barren account of how knowledgeable persons make their way among multiply interrelated settings. (Lave 1996, p151).

\section{Introduction}

Within writing and thinking about learning from a cognitive psychology perspective, the concept of transfer of learning has long been seen as of central importance. Haskell (2001) opens his book, titled The Transfer of Learning, with the following words:

Transfer of learning is our use of past learning when learning something new and the application of that learning to both similar and new situations.... Transfer of learning ... is the very foundation of learning, thinking and problem solving. (p. xiii)

This claim about the importance of learning transfer is immediately followed by the identification of an equally major problem:

Despite the importance of transfer of learning, research findings over the past nine decades clearly show that as individuals, and as educational institutions, we have failed to achieve transfer of learning at any significant level. (p xiii).

In the body of the book, Haskell goes on to present a new framework for understanding and achieving the transfer of learning. However, there is a deep paradox in his opening paragraph, which warrants direct attention. In the quotes given above, he claims both that learning transfer is the foundation of learning, thinking and problem solving, and also that individuals and educational institutions have failed to do it. If both these statements were true, it would follow that humankind was still largely incapable of learning, thinking or problem solving. Yet our everyday experiences and the history of human progress suggest the opposite is true.

For us, however, the problem is not that learning transfer is both essential and almost impossible, rather in this paper we vigorously question the whole strategy of using the metaphor of learning transfer for trying to understand what happens when people learn something new and/or move into new and different situations. Much contemporary educational policy continues to make simplistic, 'common-sense' assumptions about the transfer of learning that are directly contradicted by much of the research and theorising of learning that has occurred over the last decade and more. This situation is further complicated by the fact that some researchers wish to hold on to the concept of learning transfer even though this is rooted in those same simplistic notions of learning. What is especially revealing in much policy literature is 
the way the two metaphors of learning transfer and learning as acquisition are employed ubiquitously to reinforce and support one another. The same is true in some academic literature (e.g. Sfard 1998).

But according to the best available research literature, even researchers who wish to retain the metaphor of transfer tell us that it is anything but ubiquitous. We have already cited Haskell (2001). In similar vein, despite increasing power of experimental techniques, transfer "seems to vanish when experimenters try to pin it down" (Schoenfeld 1999, p. 7). Accepting that transfer is indeed rare if it is restricted to 'replicative' transfer, Bransford \& Schwartz (1999) point to the need to reconceptualise transfer and, by implication, learning. They propose that we broaden the notion of 'transfer' by including an emphasis on 'preparation for future learning', the ability to learn in new environments. According to them, the point of transfer is not replication, but a contribution to facilitating ongoing learning. It seems that rather than any common-sense conception of direct transfer being applicable to typical life situations, it is more realistic to view 'transfer' as renovation and expansion of previous knowledge via the experience of dealing with new situations in new settings. Here, learning is more accurately viewed as an ongoing process than as a series of discrete acquisition events. If this is the norm for learning, then both the transfer and acquisition metaphors threaten to muddy and mislead our thinking about learning. They simply omit the crucial importance to learning of changing contexts. As we will argue in this paper, learning is more fruitfully viewed as an ongoing process rather than as a series of acquisition events. We will be looking for concepts and metaphors to enhance this alternative understanding of learning.

We are not the first authors to explore the debate between those pro the notion of learning transfer, and those against. This debate is an integral part of an academic struggle between two different schools of theorising about learning. The detail of these debates had been thoroughly documented elsewhere (Tuomi-Gröhn \& Engeström 2003a). What is largely missing in this debate is an understanding that transfer is a metaphor for a complex set of processes (but see Saljö 2003). Our argument here is that as a metaphor, the term transfer brings associated baggage that leads to a continuing misunderstanding of the processes it stands for, and that this particular metaphor should be abandoned.

In earlier work (Hager 2004a) attention has been drawn to the seeming inescapability of employing metaphors in thought and talk about learning. Hodkinson (2004) supports this view, and argues that learning is a conceptual and linguistic construction that is widely used in many societies and cultures, but with very different meanings, which are at least partly contradictory and contested. Put differently, there is no external, reified entity that is 'learning'. Rather, people construct and label certain processes/activities/products as 'learning' (Saljö 2003). Transfer and the closely connected idea of acquisition are amongst the commonest metaphors employed in thought and talk about learning. Yet transfer and acquisition are merely two learning metaphors amongst many. If transfer is as rare as the research suggests, then perhaps the acquisition metaphor has been overused, even to the extent of distorting our thought and talk about learning. How to best get a handle on alternative metaphors?

Currently, there is no available single general account of learning. Rather there are various ways of understanding learning. To get beyond an over-simplistic polarisation 
between two alternative schools of thinking about learning (Anderson et al. 1996, 1997; Greeno 1997), and to clear the ground before engaging more directly with Tuomi-Gröhn and Engeström's (2003a,b) argument that boundary crossing is a different and better way to understand transfer, we call these various ways of understanding learning 'conceptual lenses'. There are many of these within the learning literature, but we restrict ourselves to four. Each conceptual lens offers an explanatory account of some kind(s) of learning with each different conceptual lens involving its own distinctive cluster of metaphors and assumptions. We maintain that the multiplicity of conceptual lenses reflects the fact that learning is a contested concept. Winch argues that there are many and diverse cases of learning, each subject to "constraints in a variety of contexts and cultures" which preclude them from being treated in a general way (1998, p. 85). Thus each conceptual lens for understanding learning covers some kinds of learning better than it does others. This means that to rely exclusively on one particular conceptual lens and its associated metaphors for understanding learning is to limit understanding in advance. Yet precisely this has been the prevailing tendency in educational literature, most of it based on the transfer and acquisition metaphors. The main strategy in this paper will be to flesh out these ideas by identifying some of the very significant and different conceptual lenses that are available for understanding learning. We argue that transfer and acquisition are central to two such lenses. We argue further that if a combination of two alternative lenses is adopted, it becomes much easier to understand the learning that is entailed if a person moves from one context to another - the fundamental conditions for transfer.

\section{Types of conceptual lenses for understanding learning}

\section{(a) The propositional learning lens}

A popular and widely employed conceptual lens for understanding learning is the propositional learning lens. This lens is used to explain the learning of facts, concepts, propositions and the like. It centres on the notion of acquisition as its prime metaphor, but this is invariably accompanied by the associated metaphor of transfer. So fixed are acquisition and transfer in the popular mind that this conceptual lens can be dubbed the 'common-sense account of learning'. This is closely related to what Beckett and Hager (2002, pp. 96-98) call the 'standard paradigm of learning' . However, whereas their discussion centres on the broad features of learning and learning practices, our focus here is on the specific metaphors themselves and how they lead, as well as mislead, our understanding of learning. The propositional learning lens connotes still further metaphors by implying that the mind is a 'container' of 'knowledge as a type of substance' (Lakoff \& Johnson 1980). Thus, acquisition of knowledge becomes movement of entities into a container, out of which they can be transferred as required (cf. Freire (1970) on "banking education").

Under the influence of the mind-as-container metaphor, knowledge is treated as consisting of objects contained in individual minds, something like the contents of mental filing cabinets.

(Bereiter 2002, p. 179)

This theory highlights learning as the accumulation of products. But the processes of learning by which this supposed accumulation occurs, are overlooked. Exactly how acquisition and transfer are supposed to happen is not addressed.

We argue that the acquisition and transfer metaphors that characterise this conceptual 
lens, colour our understanding learning with the following three basic assumptions:

1. What is learnt is a product, a thing or substance that is independent of the learner. This assumption underpins the whole web of common-sense notions about learning, such as the idea that as well as in minds, this independent thing can be stored in other suitable receptacles (books, libraries, CDRoms, etc). Also, just as many people can read the same book, so the various learners in a group can achieve identical learning, i.e. their minds can each acquire the same something that is independent of any one of them. Later we will suggest that there are important kinds of learning for which this independence assumption does not apply.

2. Learning involves movement of this thing or substance from place to place. This assumption underpins the acquisition and transfer metaphors. The metaphors encourage the common-sense notion of a commodity or substance being literally moved from one location to another. For instance, someone learns ' $x$ ' at location ' $y$ ', then moves to location ' $z$ ' where they use ' $x$ ' (i.e. transfer it at the new location). Or, knowledge is transferred from a teacher to a learner. Here the supposed movement must be more complex, and puzzling, since the teacher also retains what was transferred to the learner. In fact, the metaphors are already misleading us.

3. What is learnt is independent of and separate from the context in which it is learnt. The decontextualised learner that acquires and transfers independent items of learning has strong roots in Western philosophical and epistemological traditions that are by now widely discredited. Yet uncritical employment of the acquisition and transfer metaphors entrenches this dual separation of both the learner, as spectator mind, and the learning from the context in which it is learnt. Later we will argue that some important types of learning are significantly and irreducibly contextual. Over-reliance on the propositional learning lens for understanding learning renders these important types of learning invisible.

Of course, propositional learning covers more than just acquisition of true isolated propositions. The learner also needs to know how various propositions relate to one another, how propositions are validated, etc. (e.g., see Winch 1998, p. 16). These matters are beyond the scope of this paper. However, one significant result of engaging in this further elaboration and discussion of propositional learning would be that it would identify further metaphors, such as certain concepts being dubbed as 'central', 'key', 'basic' or 'fundamental'; or the ‘surface' learning/'deep' learning distinction.

Practices and processes within formal education systems, such as curriculum and assessment, have been strongly shaped by assumptions associated with the propositional learning lens. With formal education having been compulsory for well over a century, the public has been well and truly 'schooled' to accept that propositional learning is the 'natural' kind of learning, with acquisition and transfer being its characteristic features (Hager 2005a).

The influence of the acquisition and transfer metaphors is apparent in the widespread perception that success in quiz shows is evidence of substantial learning. This popular quiz show view of learning makes a series of assumptions, each closely related to the transfer metaphor: 
- All questions have a correct answer.

- The summit of learning achievement is the ability to answer all questions correctly.

- The extent of learning can be accurately and numerically gauged (e.g., as \% of correct answers).

But the quiz show notion of learning is actually very limited and partial. Expertise in a discipline does not involve memorisation of prodigious amounts of factual propositional knowledge. Instead, disciplinary experts know what factual information is useful in a particular situation, where and how to access this information as required, and how to use it in the given situation. Though they can readily call to mind a range of propositional knowledge relating to their discipline, their detailed understanding of the discipline consists as much in a capacity to access and deploy a much greater range of propositional knowledge that they have no need or inclination to memorise. This latter capacity involves various kinds of know how that may not all be codifiable as a set of true propositions. This is why experts might not always excel as expected in a quiz show situation, especially where the questions are at a level well beyond the elementary. The same kinds of considerations apply even more so to expertise in more practical activities, where there is no one correct way to proceed and where much of the knowledge involves tacit dimensions.

Is propositional learning important qua learning? Our answer is a qualified 'possibly, for some specific purposes', e.g. when calling on one's knowledge of multiplication tables or competing in a quiz show. However, such uses of this lens should always be located within broader views of learning, which will be explored later. What is more, the widespread use of this lens unhelpfully reinforces use of the acquisition and transfer metaphors. In stark contrast to the Lave quotation that opens this paper, Sfard (1998, p. 9) has claimed that we have to retain the acquisition metaphor, in order to make sense of learning transfer. However, we question whether acquisition can explain transfer, since we think that the notion of transfer actually smuggles in acquisition with it. In any case, we maintain that both of these metaphors have been over-used to the point of mystifying learning more than explaining it. Our reasons for this claim will become clear in the following sections.

\section{(b) The skill learning lens}

Another popular conceptual lens for understanding learning is the skill learning lens. In many respects its assumptions parallel the propositional learning lens, but its distinctiveness lies in its focus is on skills instead of propositions. Its major assumptions are:

1. What is learnt is a thing or substance that is independent of the learner. This is captured in popular discourse about skills, e.g. 'gaining skills', 'passing skills on from one generation to the next', 'either use them or you lose them'. However, whereas propositions, were supposed to enter the learner's mind, skills are things that somehow lodge in the learner's body. That skills are independent of the learner is shown by the fact that different learners can all acquire the same skill.

2. Learning involves movement of this thing or substance from place to place. This raises parallel issues and problems to those outlined previously for the equivalent assumption in the propositional learning lens. Once again, there appears to be literal movement (e.g. transfer of a skill from worksite A to worksite B). But, once again, it 
is dubious that teachers literally transfer their skills to learners. Rather a new instance of the skill seems to be created in the learner's body, so again the metaphor misleads.

3. What is learnt is separate from and independent of the context in which it is learnt. The popularity of this assumption is evident from the current enthusiasm for generic skills. As nations have sought to respond to globalisation by enriching, expanding and better recognising the skills profiles of their labour force, policies to promote and reward so-called 'generic skills', such as employability skills, key skills, and learning to learn skills have become common at all levels of education systems. Once acquired, it is assumed that these skills can be transferred unproblematically by learners to diverse situations. Yet as contemporary theoretical and research-based accounts of learning at work suggest (Hager \& Holland 2006), the contextuality of actual work processes severely curtails naïve expectations of unproblematic generic transfer. It seems that this assumption, that what is learnt is independent of the context in which it is learnt, underpins common attempts to specify occupations in terms of a list of competence statements. Such competence statements have proliferated in recent years, but the results of their use have been mixed at best (Hager 2004b). It seems that skilful practice of occupations is both holistic and significantly contextual, rather than atomistic and context-free, as is assumed by naïve use of competence statements.

We argue that uncritical adoption of the acquisition and transfer metaphors underpins the naïve uses of competence statements. But, importantly, there is a major difference between propositional learning and skill learning that renders the acquisition and transfer metaphors even more dubious for explaining skill learning. This major difference lies in the often overlooked reality that while we are able to accurately specify propositions, the precise specification of skills is much more elusive. Much about skills remains implicit and tacit. Attempts to describe precisely the human capacities that underpin successful performance are always somewhat speculative and, hence, are subject to contestation and revision (for fuller discussion see Hager 2004b). This crucial fact is so often overlooked because descriptions of performance outcomes (which can be specified accurately) are taken to be descriptions of the human skills, abilities, and capacities that enable these outcomes. So the relative concreteness of the former is falsely attributed to the latter. But, importantly, the acquisition and transfer metaphors refer to the skills, abilities, and capacities involved in performance, not to performance outcomes. Thus the central metaphors about skill learning attach to what is in principle imprecise, and pass by those aspects that are amenable to precise specification. Unsurprisingly, then, the skill learning literature is replete with confusion about the nature of skills.

However, somewhat balancing this problem is a growing recognition in recent literature of the importance of types of dispositional learning that are largely implicit and tacit (e.g. Winch 1998). For understanding learning in general, this shifts the spotlight right away from a one-sided emphasis on propositions being acquired by minds. Overall, the skill learning lens has some important similarities to the propositional learning lens, but its distinctive differences provide new reasons to question the acquisition and transfer metaphors.

We have seen that the acquisition and transfer metaphors support the seeming common-sense that lies behind the first two conceptual lenses for understanding learning. However, we have argued that these two lenses provide, at best, misleading 
and partial understandings of learning. Understandings that if relied on too heavily serve to distort and weaken educational thought and practice. Instead, we wish to propose an understanding of learning that rejects each of the above three assumptions, thereby revealing the acquisition and transfer metaphors to be inappropriate.

(c) The learning through participation in human practices lens

A third important and recently influential conceptual lens for understanding learning is the learning through participation in human practices lens. This lens focuses on the ways in which people learn, through participating in contextual and culturally grounded activities. This and the following lens are closely related to what Beckett and Hager (2002, pp. 146-51) call the 'emerging paradigm of learning'. However, they concentrate on the broad features of learning and learning practices, whereas our focus is on dominant metaphors and how they shape our understanding of learning. One early version of the learning through participation in practices metaphor focuses on the initiation and education of people into performance of human practices of all kinds (Lave \& Wenger 1991). Other studies focus on the on-going learning through participating in activities, for example in the workplace (e.g. Hodkinson \& Hodkinson 2004a). The dominant metaphor for this lens is participation. Subsidiary metaphors include learning as activity and, for beginners, ideas such as 'finding your way around' the field of practice and terms that denote either level of attainment (e.g. 'second year apprentice', 'journeyman') or level of acceptance within the community of practitioners (e.g. ‘legitimate peripheral participation’ (Lave \& Wenger 1991)).

Fundamental assumptions underpinning this conceptual lens for understanding learning are:

1. What is learnt is a complex social construction that subsumes the individual learner.

With this lens, the nature of what is learnt has changed. Rather than being the thing or substance of the first two conceptual lenses, what is learnt is now a complex entity that extends well beyond the learner; a set of more or less complex practices; a social construction undergoing continuous change. The learner learns by active participation in the practices and is gradually subsumed into the complex social construction that is the evolving set of practices. Clearly, within this lens, learning is not seen as independent from the learner in the particular ways that it was in the earlier lenses. However, the practices will have a history that is not dependent on the participation of any given learner. A limitation of this lens is that in integrating the individual learner into a social participatory process, the sense of the individual life history, dispositions and agency of each learner is lost (Billett 2001; Hodkinson \& Hodkinson 2004b). However, what is learnt is more complex than in the previous lenses, for it is evident that the learning cannot be located fully within the learner. As well, communities of practice feature the possibility, indeed the likelihood, of communal learning, i.e. learning by teams and organisations that is not simply reducible to individual learning (Toulmin 1999). Toulmin notes that understandings of learning need to account for both “'knowledge' as the possession of individuals and 'knowledge' as the collective property of communities of 'knowers'...” (Toulmin 1999, p. 54). So, for the participation in human practices lens, human practices extend well beyond any individual practitioner.

2. Learning for newcomers involves movement of the learner from insignificance to 
greater prominence as they engage in the practice to be learnt.

This assumption also provides an instructive difference from the corresponding assumption for the first two conceptual lenses. They posited movement of what was learnt. But, as the participation metaphor suggests, it is the learner that moves rather than what is learnt. The practice is normally something that is 'there' well before learners start to engage in it. Learners move within the practice from novices to, mostly, proficient performers; from legitimate peripheral to full participation. It is writing from this perspective that Lave penned the quotation attacking the transfer metaphor, with which we headed this paper. Within the participation lens, the learning of newcomers is not now the prime focus. Wenger (1998), for example, sees legitimate peripheral participation as a special case.

3. What is learnt is significantly shaped by the context in which it is learnt. This assumption rejects the corresponding assumption for the first two conceptual lenses. They both aimed to de-contextualise learning, though with very mixed success. But, much of the initial plausibility of the acquisition and transfer metaphors stems from the notion that learning transcends context. The learning through participation lens, with its prime focus on the participation metaphor, thereby portrays learning as inherently contextual, thus directly challenging the value of the acquisition and transfer metaphors. Acceptance of the idea that learning has contextual features entails the likelihood of the learner modifying and adapting earlier learning to handle a related situation in a new context. This is a normal occurrence in all kinds of human practices. It is also a much more complex situation than the 'acquire it and transfer it' model takes it to be.

4. Learning (and the learner) change as contexts change.

This assumption further reflects the complexity of this lens compared to the previous two. The idea that the learning and the learner both change with context becomes vital as the participation lens is directed onto the learning of experienced learners, rather than on that of novices, as in the early work of Lave and Wenger.

However the participation metaphor can be charged with embedding the learning so completely within the given context that it is remains a mystery exactly how individuals are reshaped (another metaphor) by their learning. It might be maintained against participation theories that they say too little about the individual's learning as their personal identity changes from a novice to a full participant. This deficiency in the Lave and Wenger account has been discussed by several critics (e.g. Elkjaer 2003, Guile \& Young 1999).

A further problem with much writing within the participation lens is that it tends to concentrate upon one context for learning. Studies tend to engage with learning within one workplace. The more the focus switches to the learning of experienced workers, the greater is the tendency to bracket off what happened in previous locations, or what might happen in future ones. For this reason, the participatory lens has relatively little to say about the supposed phenomenon of transfer - an omission that we are attempting to address.

By bringing contextuality to the fore, the learning through participation lens challenges earlier assumptions about uniformity in what is to be learnt. Rather than thinking of learning for a designated practice as a standard list of items to be acquired 
by all would be practitioners, a person's practice is better viewed as participation in a continually evolving process. The constant appearance of novel situations, new kinds of equipment, local traditions or preferences, etc., mean that learning needed for successful practice is continuous and not specifiable in advance. Proficiency in a particular area of practice, may not easily translate to proficiency in neighbouring areas of practice. In circumstances such as these, where learning (participation) is a continually evolving process, transfer and acquisition no longer appeal as general explanatory concepts.

We would argue that all human learning entails participation in a social context, even if that context is a desert island, or preparing for a quiz show. However, this is not the same as claiming that the lens of learning as participation alone can adequately explain all learning. More specifically, it cannot offer a complete explanation of all learning for all purposes.

\section{(d) The learning as transformation or reconstruction lens}

A fourth important and common type of conceptual lens for understanding learning is the learning as transformation or reconstruction lens. This invokes the major metaphors of the transformation or reconstruction of the learner and/or of their environment. Within this lens, there are two variations. Within the intellectual movement sometimes termed constructivism, the emphasis is firmly on transformation or reconstruction within the individual learner. Perhaps because of the impact of constructivism within the fields of mathematics and science education, there is often a concentration on propositional knowledge. Within the constructivism learning lens, science, say, entails the transformation and reconstruction of what is already known by the learner. Thus, Chinn and Brewer (1993) write about the ways in which pre-existing schemata can inhibit the understanding of science. Subsidiary metaphors include 'scaffolding' - the notion that new learning is built on existing understanding, as bricks are added to an existing wall. The learner is transformed into a scientist, as a wall is transformed into a building. As with learning through participation, this lens sees what is learned as changing, as each learner reconstructs their own understanding. However, within this perspective, the significance of context in relation to learning is often overlooked.

In this variation of construction, the individual changes, but the context remains the same. Put differently, there is an acknowledged influence of context on learning, but not vice versa. In radical versions of constructivism, what is learned changes also, as each learner constructs their own understanding of science. In less radical versions, much important knowledge, such as the content of science, remains relatively unchanged (Phillips 1995). The issue then is simply how students can be helped to construct a correct understanding.

A second variant of learning as reconstruction can be found in Engestrom's (2001) version of activity theory. The focus now is on the activity system as a whole - it is the system that changes, usually as a result of either internal or external contradictions or pressures. This time, the context in which individual learners work and learn changes, and they change with it. However, the emphasis remains on the impact that a changing context has on individual learners, rather than the other way around.

Fundamental assumptions underpinning this conceptual lens for understanding 
learning are:

1. The learner is an integral part of the learning, and sometimes of what is learnt.

2. Learning is an evolving process that includes the learner evolving.

3. Learning involves emergence of novelty as new understandings and/or new contexts are formed.

The problem is that very little of the literature adopting this lens addresses both individual change and changing context. There is also very little work within this lens that explicitly addresses transfer.

In what follows, we attempt to do two things, which are linked. Firstly, we show how it is possible to combine aspects of the participatory lens with aspects of both variations of the reconstruction lens. By so doing, we argue, the problem of splitting the individual learner from the context can be overcome. Secondly, we go on to show how adopting this new position reveals a simpler and more productive way of considering those issues that are usually addressed through the metaphor of transfer.

\section{An Alternative to Transfer}

We are by no means the first authors to suggest that learning transfer is an unsatisfactory way of understanding learning. For reasons explained earlier, writers from what we have termed broadly participatory perspectives have consistently found the metaphor unsatisfactory. Despite this academic history, one of the reasons why the transfer metaphor has become so ubiquitous and persistent may be the lack of a clear alternative. There are significant issues and some difficult theoretical and practical problems, when people move from one location to a different one, perhaps especially from education or off the job training into work. We do not know enough about how the learning entailed in such movements can be enhanced. In what follows, we offer an alternative way of understanding and analysing these issues, which does not involve the misconceptions that the transfer metaphor entails.

Perhaps the most significant progress towards an alternative thus far can be found in the contributions to Tuomi-Gröhn and Engeström (2003b). The central concept used to explain transfer in their book is boundary crossing. The use of one metaphor (boundary crossing) to explain another (transfer) may arise because the European Network in question (COST Action A11) had transfer as one of its explicit foci. Nevertheless, the retention of both terms by most contributors weakens the argument in the book. This is because it leaves the term 'transfer' unchallenged, which, in our view, undermines the attempt to distance the authors from some of its conceptual baggage. This creates problems which relate to what are identified in the collection as two key transfer issues. They are the relationship between school knowledge and the knowledge acquired in working life, and the relationship between transfer and boundary crossing. Our argument here is that boundary crossing is a valuable contribution to the replacement of transfer as a metaphor altogether, and that the discussion in the book on the relationship between school and working knowledge confuses the problem of replacing transfer by retaining the focus on the content which is learned, rather than shifting the focus to the process of learning.

In our view, there are two key steps that are necessary in moving beyond the transfer 
metaphor. This first, which has already been addressed, is the importance of remembering that transfer is a metaphor, not a literal reality (Saljö 2003). TuomiGröhn et al. (2003) make this mistake in explicitly focussing on the need to achieve learning transfer, and the value of boundary crossing as a tool for this purpose. Beach (2003) is more aware of this problem, arguing for the metaphor of transition instead of transfer. Central to Beach's argument lies the second move that is necessary to provide an alternative to transfer: the recognition that it is people who move, not knowledge or learning. However, Beach does not fully pursue this part of his analysis in the 2003 chapter, being more concerned with how learners and social organizations interrelate to each other, through a mutually constitutive developmental process of generalisation.

In the same volume, Guile and Young (2003) see what, following Beach (1999, 2003), they term 'consequential transition' not as an alternative to transfer, but as one of three useful ways of understanding transfer. The other two are: a form of expanded learning and the recontextualisation of activities between different contexts. Whilst recognising the value of Beach's work, they argue that it is insufficient in addressing the contribution that formal education can make to work based learning. This is because he focuses almost exclusively on learning in work, related to workplace activity and workplace relations. We have no quarrel with the significance of Guile and Young's three useful ways of understanding. Our challenge to them is that none of these three ways of understanding actually relates to transfer. That is, in none of the three involves knowledge seen as an object transferred from one location to another. Rather, we see all three of their ways of understanding as invoking processes of change. Furthermore, though changes can be made both to vocational education and to workplaces to enhance the relationships between them, the changes implied by their three ways of understanding transfer are all made by the person who crosses boundaries - helped or hindered (often both!!) by other people and by the situations between which s/he moves.

This failure to follow through on the movement of people from one location to another is linked to the concern within Tuomi-Gröhn and Engeström (2003) with the relationship between school and working knowledge. That is, the assumption is that knowledge is the central concern of the transfer debate. Our argument is that the successful move from one location to another, such as from school to work, is not a matter of knowledge transfer or of knowledge generalisability. It is an issue about learning.

Even within the pro-transfer literature, there is an increasing awareness that what they term 'transfer' is a process, which entails learning before the physical move (Bransford \& Schwartz 1999) and learning after it (Eraut 2004). Put differently, by borrowing terminology from Beach $(1999,2003)$ boundary crossing from one location to another is always a process of transition. Beach (2003) argues that this transition can be understood as a change in an individual, in the activity the individual engages with, or both. Our concern is with the former, as influenced by the latter.

The starting point for this alternative to the transfer metaphor is the observation that, as the contributors to Tuomi-Gröhn and Engeström (2003) also recognise, the person who moves is not a 'vessel' containing 'stuff', to use Bereiter's (2002) folk theory terminology. Rather, we are talking about a person whose social and embodied self 
includes skills, knowledge and understanding. These can be understood as integral parts of the person. Each person has constructed that skill or knowledge as part of themselves. Here learning is viewed as a relational web, a process of ongoing change. It connects the learner to the surrounding world in an evolving way. Learning is transactional in that it changes both the learner and the context, viewed both widely and narrowly. Most generally, learning is a change in both the learner and its environment.

It follows that when a person joins a new workplace they bring within themselves much more than skills or knowledge. Rather, they bring experience. Here Dewey's "technical definition of education" is pertinent:

It is that reconstruction or reorganisation of experience which adds to the meaning of experience, and which increases ability to direct the course of subsequent experience. (1916, p. 76)

This view rejects each of the three assumptions of the common-sense accounts of learning (1-3 above), replacing them as follows:

i. Far from being a thing or substance, learning is a changing relational web. Nor is learning independent of the learner, since the learner is a part of this changing relational web.

ii. Rather than involving movement of a thing or substance from place to place, learning consists of a relational web in a process of ongoing change.

iii. Rather than what is learnt being separate from and independent of the context in which it is learnt, learning is inherently part of and shaped by its context.

As academics and researchers we need ways of analysing what experience means for learning that minimise dangers of reductionism. One way is to draw upon some of the concepts of Pierre Bourdieu. From this perspective, what an experienced person brings to a new situation is a combination of dispositions and capital.

For Bourdieu, the dispositions that make up a person's habitus are deep-seated orientations that strongly influence their actions in any situation (Bourdieu \& Wacquant 1992). These dispositions develop throughout people's lives. A person's dispositions may equip them better or worse for any particular situation, such as a new workplace. If two new employees begin at the same time, differences in the appropriateness of their dispositions may help explain why one succeeds more than the other. Bourdieu also writes about different types of capital - cultural, social, economic and symbolic. Despite the way in which these concepts are sometimes used by others, Bourdieu himself is explicit that capital is relative to the field within which it is used (Bourdieu \& Wacquant 1992). Indeed, as Okano (1993) shows, some forms of capital can actually hinder progress and achievement in a field where they have negative value. One simple example related to symbolic capital is the reluctance of some employers to take on an applicant who is 'over qualified'. All forms of capital can be important in explaining and understanding location change, but when focussing on the particular issues that concern the learning transfer literature, cultural capital is arguably the most significant. Cultural capital can be paraphrased as knowing how to succeed in a particular field. In a workplace, this would include skills knowledge and understanding of the particular practices of that workplace including subtleties of social relations and social hierarchies. It is the possession of this cultural capital that separates out what Lave and Wenger (1991) term full members from 
newcomers. Thus, in ways parallel to and interrelated with dispositions, cultural capital acquired prior to entering a firm can be highly significant in the ability to fit in and to do the job once appointed. These concepts, with the more general term 'experience', allow us to reposition and reconceptualise skills and vocational knowledge. Rather than reified and isolatable phenomema, they become an integral part of a person's wider dispositions and capital and an integral part of the social practice of doing the job.

This last claim requires some expansion. We are not claiming that either skills or knowledge can have no independent existence outside the person. It is quite proper for both to be examined from the perspective of the workplace or educational context. Also, there is nothing in our argument to directly challenge Guile and Young (2003), when they claim that there are fundamental differences between what they term vertical, generalisable academic knowledge and horizontal workplace knowledge. What we do claim is that whatever the types of knowledge or skill with which we are concerned, they become changed and reconstituted within the person who has gone through and is going through a learning process. Put differently, the laws of physics or chemistry exist independently of any individual. However, a person who knows some of the laws of physics knows and understands them in a partly individualistic way. The gap between the abstract generalisable law and what a person understands about that law is one reason why even the best university physics students usually achieve less than $100 \%$ in examinations. Similarly, the skills, knowledge and understanding developed through workplace practice are also reconstituted within each individual worker. Not all workers understand their shared practices in exactly the same way. As Billett and Somerville (2004) argue, it is a mistake to overlook the significance of individual learners in relation to workplace learning. We would add, in educational learning too (Bloomer \& Hodkinson 2000). It is this reconstitution of knowledge and skills that matters when understanding the transition across boundaries.

The next step in our alternative conceptual framework is to adopt the metaphor of learning as becoming, as a similarly holistic way of understanding learning as a process. As has already been explained, this entails understanding learning as social and embodied (practical, physical and emotional, as well as cognitive). Thus, when a learner constructs or reconstructs knowledge or skills, they are also reconstructing themselves. Beach (1999) recognises this element of personal reconstruction, but does not, in our view, fully address the social and embodied nature of that reconstruction. Such personal reconstruction is sometimes explicit and agentic, but much of it is tacit from the perspective of the person concerned. That is, people become through learning and learn through becoming whether they wish to do so or not, and whether they are aware of the process or not.

Using the metaphor of becoming to understand learning does not entail a fixed state of having become. Put differently, there is not always a clear endpoint to learning, though sometimes, of course, either the learner or others may be explicitly concerned with one. Employers are often concerned with how well and, increasingly, how quickly a new worker becomes fully functional within their working practices. Similarly, many trainees are directly concerned to become a teacher, social worker, chef, shop worker or engineer. However, such end points are simplifications and also are somewhat arbitrary stages in the on-going learning process. It is well known that 
fully trained 'full members' of a workplace culture continue to learn (see Hodkinson \& Hodkinson 2004a, 2004b, for one example). The metaphor of becoming entails this sense that learning is never complete. As Saljö (2003, p. 315) argues "people simply cannot avoid learning”. Learning as becoming ends with death, or with a permanently comatose state. It is for this reason that it is difficult to identify when learning to be, say, a teacher starts or ends. It starts well before any formal educational training, and ends well after the first teaching appointment.

As research has shown (Bloomer \& Hodkinson 2000), the ways in which people learn on vocational courses is influenced by their prior positions, experiences, dispositions and capital. Put differently, the process of learning as becoming was already well underway, before the course started. The ways in which a person (re)constructs themselves and that which they are taught is influenced by the person they had already become when a course starts. The same research also shows that whilst on a course, learning is influenced by experiences outside the course itself, as people live their lives. This process of living also entails learning as becoming: in the family, the local community, in leisure. Even when a person sees their educational learning as separate from the other parts of their life, strong influences remain. At a simple level, these can be seen as practical considerations - time pressures, conflicting demands, lack or presence of social support, etc. However, life outside the course also influences a person's dispositions and sense of self. Bloomer and Hodkinson (2000) show how one young woman's experiences outside her college course led directly to her abandoning the course to look after her sick partner. Though strongly influenced by lack of economic resources, this abandonment was also related to her gendered dispositions about family roles, and her abandonment was an integral part of a further reconstruction of her sense of self, as her dispositions towards college and a future career changed.

Research also shows that performing and learning at work is influenced by the positions, dispositions and capital developed in a person prior to being employed. This concerns much more than the knowledge and skills they learned whilst on a vocational course. Bowman et al. (2005) studied a small number of UK fulltime Masters degree students. On the two vocational courses studied, interpreting and a specialised employment-focussed applied engineering course, those who moved successfully into related employment often had prior non-educational experiences directly relevant to that employment. That is, they had developed relevant social and cultural capital that other equally successful students lacked. The value of the courses to those who moved into jobs in related areas was that they added to and further developed not just knowledge and skills of doing the job, but formed a valuable part of the on-going process of becoming an interpreter or applied engineer. This entailed much of what Guile and Young (2003) would term horizontal knowledge about their desired professions, as well as expanding their relevant social and cultural capital through meeting people working in those professions. In these particular examples, participating in the course made a contribution to the process of becoming an interpreter or applied engineer. However, course experiences helped others to learn that they did not want to follow the chosen career, and others found that despite succeeding on the courses, suitable jobs were unattainable. Learning on the courses changed some into people who no longer wanted to be applied engineers or interpreters. For the others, who had further developed these ambitions as part of their dispositions and sense of self, the courses resulted in at least a temporary sense 
of dislocation, between that sense of self and the restricted opportunity structures of the labour market (Roberts 1968).

Once in a job, Bowman et al.'s (2005) research shows that learning as becoming continued, and was influenced by far more than just their already developed positions, dispositions and capitals, even though all these remained important. For example, the researchers followed two students who successfully obtained the prestigious EU interpreter traineeships. The one who had additional relevant experiences of living abroad, adapted more quickly to living in Brussels and passed the very difficult EU test, which allowed her to be placed on the approved EU list of translators. The other person failed this test. Once she got over the initial devastation and sense of failure, she worked to develop her own freelance contacts, and succeeded in getting interpreting work without the help of the EU. She rapidly discovered that within the field, her participation in the EU training mattered much more than whether she passed or not. When the research fieldwork finished, 18 months after the MA course finished, this second person, who had failed the EU test was much more successfully established in an interpreting career than her friend who passed. Her learning to become an interpreter was both more advanced and more successful, at that point in time.

For those Masters students not following vocational courses, or for those students following such courses but who either chose or were forced to change career direction, there was a lengthy period of learning through a range of jobs and other experiences, before anything resembling a settled career was begun. Bowman et al. (2005) document, for example, the ways in which temporary jobs and other changes in a person's life contributed to an often non-linear personal transition or even transformation. Learning for these people involved significant career shifts, and Bowman et al. showed how these career shifts entailed further dispositional change. However, they also showed that the experiences of undertaking the Masters degree, as well as the learning alongside their studying and in their previous lives strongly influenced that new learning. They also show how important economic, social and cultural capital were in this learning and career development.

\section{Conclusion}

Our argument, then, is that we should cease thinking and writing about 'learning transfer' and think instead of learning as becoming within a transitional process of boundary crossing. There are three parts to our rejection of the metaphor of learning transfer. The first, as others have also recognised, is that it presents a misleading way of understanding learning, which is at odds with much current theorising and empirical evidence. The second is that a focus on transfer over-emphasises the importance of educational knowledge in the transition from education into work, even on specific vocational courses. We are not claiming that such knowledge has no value - simply that it must be understood as but one contributory factor. Its importance will depend on particular circumstances, relating to the career concerned and the person making the transfer. Thirdly, the metaphor of transfer is damaging and even dangerous in practice, as it reinforces rather than challenges Bereiter's (2002) folk theory of learning. This folk theory underpins misguided efforts by employers, politicians and educators who seem at times desperate to change educational course provision in order to provide the 'knowledge' that will render more efficient the 
progress from education into work, and directly contribute to improved work performance.

It follows that when writers like many of those contributing to Tuomi-Gröhn and Engeström (2003) consider the relationship between learning in education and learning in work, they should cease to locate this valuable research within the metaphor of transfer. It is important to see the relationship between educational and workplace knowledge, and between educational knowledge and work performance, as part of a learning transition instead.

In our view, by seeing knowledge and skills transfer as the dominant issue, such researchers often exaggerate the problems of that learning transition. Research shows that for some people and in some contexts, the relationships between educational and workplace knowledge are already fairly unproblematic. Fuller and Unwin (2003) for example, describe one very successful engineering apprenticeship. What distinguished this from others that were less successful were the facts that (i) the employer and college had mutual respect developed over a long period of time, (ii) the employer and workers valued what the apprentices were learning off the job, and (iii) the expansive learning environment in the workplace itself. The content of the college course was but a part of this wider success story.

This returns us to the quotes from Haskell (2001) with which we began this paper. Despite the claims of advocates of learning transfer, and also of Tuomi-Gröhn et al. (2003), that learning transfer is very difficult, very many people regularly undergo a successful learning transition from student into worker, in very many occupations. The metaphor of transfer mis-constructs the main problem as one of knowledge fit, relevance and transfer, rather than two others. They are; (i) how can this learning through transition be further enhanced, which includes a better understanding of the place education can play in such enhancement and increasingly, (ii) how can we help employers and governments learn that much of the transitional learning will take place within work, and that the best educational courses in the world will still not produce what Brown and Hesketh (2004) memorably describe as oven-ready workers.

Our alternative approach to this problem has one further advantage. Much of the work on learning transfer across boundaries focuses, as we have done here, on the boundary between education and work. But there are many other forms of boundary crossing, where the process of transitional learning is also important. These include: job changes; moves within the educational system (for example from school to university); retirement (Hodkinson et al. in press); and parenthood. A sound theory of learning across boundaries should be applicable in all such circumstances, and learning transfer, however configured, is not.

\section{References}

Anderson, J. R., Reder, L. M. \& Simon, H. A. (1996) Situated learning and education, Educational Researcher, 25(4), 5-11.

Anderson, J. R., Reder, L. M. \& Simon, H. A. (1997) Situated versus cognitive perspectives: Form versus substance. Educational Researcher, 26(1), 18-21. 
Arthur, M. B., Inkson, K. \& Pringle, J.K. (1999) The new careers: individual action \& economic change (London, Sage).

Barnett, R. (2006) Graduate attributes in an age of uncertainty, in P. Hager \& S. Holland (Eds.) Graduate attributes, learning and employability. Vol. Six: Lifelong learning series (Dordrecht, Springer).

Beach, K. (1999) Consequential transitions: a socio-cultural expedition beyond transfer in education, Review of Research in Education, 28, 46-69.

Beach, K, (2003) Consequential transitions: a developmental view of knowledge propagation through social organisations, in T. Tuomi-Gröhn \& Y. Engeström (Eds.) Between School and Work: new perspectives on transfer and boundary-crossing (Amsterdam: Elsevier Science).

Bereiter, C. (2002) Education and mind in the knowledge age (Mahwah, N.J./London, Lawrence Erlbaum Associates).

Billett, S. (2001) Learning through working life: interdependencies at work, Studies in Continuing Education, 23(1), 19-35.

Billett, S. \& Somerville. M. (2004) Transformations at work: Identity and learning, Studies in Continuing Education, 26(2), 309-326.

Bloomer, M. \& Hodkinson, P. (2000) Learning careers: continuity and change in young people's dispositions to learning, British Educational Research Journal, 26(5), 583-598.

Bourdieu, P. \& Wacquant, L.J.D. (1992) An invitation to reflexive sociology (Cambridge, Polity Press).

Bowman, H., Hodkinson, P. \& Colley, H. (2005) Employability and career progression for fulltime UK Masters students. Final Report for the Higher Education Careers Service Unit, Manchester, http://www.hecsu.ac.uk/.

Bransford, J.D. \& Schwartz, D.L. (1999) Rethinking transfer: a simple proposal with multiple implications, Review of Research in Education, 24, 61-100.

Brown, P. \& Hesketh, A. (2004) The Mismanagement of Talent: employability and jobs in the knowledge economy (Oxford: Oxford University Press).

Chinn, C.A. \& Brewer, W.F. (1993) The role of anomalous data in knowledge acquisition: a theoretical framework and implications for science instruction, Review of Educational Research, 63(1), 1-49.

Colley, H., James, D., Tedder, M. \& Diment, K. (2003) Learning as becoming in Vocational Education and Training: class, gender and the role of habitus, Journal of Vocational Education and Training, 55(4), 471-497.

Dewey, J. (1916) Democracy and Education (New York, Macmillan). 
Dominicé, P. (2000) Learning from our lives: using educational biographies with adults (San Francisco, Jossey Bass).

Elkjaer, B. (2003) Organizational learning with a pragmatic slant, International Journal of Lifelong Education, 22(5), 481-94.

Engestrom, Y. (2001) Expansive learning at work: towards an activity-theoretical reconceptualisation, Journal of Education and Work, 14(1), 133-156.

Eraut, M. (2004) Transfer of knowledge between education and workplace settings, in H. Rainbird, A. Fuller \& A. Munroe (Eds.) Workplace Learning in Context (London, Routledge).

Evans, K., Kersh, N. \& Kontiainen S. (2004). Recognition of tacit skills: sustaining learning outcomes in adult learning and work re-entry, International Journal of Training and Development, 8, 1.

Freire, P. (1970) Pedagogy of the Oppressed (London, Penguin).

Fuller, A. \& Unwin, L. (2003) Learning as apprentices in the contemporary UK workplace: creating and managing expansive and restrictive participation, Journal of Education and Work, 16(4), 407-426.

Fuller, A., Hodkinson, H., Hodkinson, P. \& Unwin, L. (2005) Learning as peripheral participation in communities of practice: a reassessment of key concepts in workplace learning, British Educational Research Journal, 31(1), 49-68.

Greeno, J. G. (1997) On claims that answer the wrong questions, Educational Researcher, 26(1), 5-17.

Guile, D., \& Young, M. (1999) Beyond the institution of apprenticeship: towards a social theory of learning as the production of knowledge, in P. Ainley \& H. Rainbird (Eds.) Apprenticeship: towards a new paradigm of learning (London, Kogan Page), 111-128.

Guile, D. \& Young, M. (2003) Transfer and transition in vocational education: some theoretical considerations, in T. Tuomi-Gröhn \& Y. Engeström (Eds.) Between School and Work: new perspectives on transfer and boundary-crossing (Amsterdam: Elsevier Science), 63-81.

Hager, P. (2004a) The inescapability of metaphors for thinking about learning, in G. Jover \& P. Villamor (Eds.) Voices of Philosophy of Education, Proceedings of the $9^{\text {th }}$ Biennial Conference of the International Network of Philosophers of Education (Madrid, Spain: Complutense University), 143-51.

Hager, P. (2004b) The competence affair, or why VET urgently needs a new understanding of learning, Journal of Vocational Education \& Training, 56(3), 409433. 
Hager, P. (2005a) Philosophical accounts of learning, Educational Philosophy and Theory, 37(5), 649-66.

Hager, P. (2005b) Current theories of workplace learning: a critical assessment, in N. Bascia, A. Cumming, A. Datnow, K. Leithwood \& D. Livingstone (Eds.) International Handbook of Educational Policy. Part Two (Dordrecht, Springer) 829846.

Hager, P. \& Holland, S. (Eds.) (2007) Graduate Attributes, Learning and Employability (Dordrecht: Springer).

Haskell, R.E. (2001) Transfer of learning: cognition, instruction and reasoning (San Diego, Academic Press).

Hodkinson, P. (2004) Theoretical constructions of workplace learning: troubling dualisms and problems of scale, ESREA Adult Education and the Labour Market Conference, Northern College, November.

Hodkinson, H. \& Hodkinson, P. (2004a) Rethinking the concept of community of practice in relation to schoolteachers' workplace learning, International Journal of Training and Development, 8(1), 21-31.

Hodkinson, P. \& Hodkinson, H. (2004b) The significance of individuals' dispositions in workplace learning: a case study of two teachers, Journal of Education and Work, 17(2), 167-182.

Hodkinson, P., Biesta, G. \& James, D. (2004) Towards a cultural theory of collegebased learning, BERA Annual Conference, UMIST, Manchester, $15^{\text {th }}-18^{\text {th }}$

September.

Hodkinson, P., Ford, G., Hawthorn, R. \& Hodkinson, H. (In Press) Retirement as a learning process, Educational Gerontology.

Lakoff, G. \& Johnson, M. (1980) Metaphors We Live By (Chicago, University of Chicago Press).

Lave, J. (1996) Teaching, as learning, in practice, Mind, Culture and Society, 3(3), 149-164.

Lave, J. \& Wenger, E. (1991) Situated learning: legitimate peripheral participation (Cambridge, Cambridge University Press).

Okano, K. (1993) School to Work Transition in Japan (Clevedon: Multi-Lingual Matters).

Passmore, J. (1980) The philosophy of teaching (London, Duckworth).

Phillips, D.C. (1995) The good, the bad, and the ugly: the many faces of constuctivism, Educational Researcher, 24(7), 5-12. 
Roberts, K. (1968) The Entry into Employment: an Approach Towards a General Theory Sociological Review, 16, 165-84.

Saljö, R. (2003) From Transfer to Boundarey-crossing, in T. Tuomi-Gröhn \& Y. Engeström (Eds.) Between School and Work: new perspectives on transfer and boundary-crossing (Amsterdam: Elsevier Science), 311-321.

Schoenfeld, A.H. (1999) Looking toward the $21^{\text {st }}$ century: challenges of educational theory and practice, Educational Researcher, 28(7), 4-14.

Sfard, A. (1998) On two metaphors for learning and the dangers of choosing just one, Educational Researcher, 27(2), 4-13.

Toulmin, S. (1999) Knowledge as shared procedures, in Y. Engestrom, R. Miettinen \& R. Punamaki (Eds.) Perspectives on Action Theory (Cambridge, Cambridge University Press).

Tuomi-Gröhn, T. \& Engeström, Y. (2003a) Conceptualising Transfer: from standard notions to developmental perspectives, in T. Tuomi-Gröhn \& Y. Engeström (Eds.) Between School and Work: new perspectives on transfer and boundary-crossing (Amsterdam: Elsevier Science), 19-38.

Tuomi-Gröhn, T. \& Engeström, Y. (2003b) (Eds.) Between School and Work: new perspectives on transfer and boundary-crossing (Amsterdam: Elsevier Science).

Tuomi-Gröhn, T., Engeström, Y. \& Young, M. (2003) From transfer to boundarycrossing between school and work as a tool for developing vocational education: an introduction, in T. Tuomi-Gröhn \& Y. Engeström (Eds.) Between School and Work: new perspectives on transfer and boundary-crossing (Amsterdam: Elsevier Science), $1-18$.

Wenger, E. (1998) Communities of practice: learning, meaning, and identity (Cambridge, Cambridge University Press).

Winch, C. (1998) The Philosophy of Human Learning, Routledge International Studies in the Philosophy of Education (London \& New York, Routledge).

Anderson, J. R., Reder, L. M. \& Simon, H. A. (1996) Situated learning and education, Educational Researcher, 25(4), 5-11. 